\title{
Endovascular embolization of head and neck tumors
}

\section{Marc A. Lazzaro ${ }^{1}$, Aamir Badruddin ${ }^{1,2}$, Osama O. Zaidat ${ }^{1,3,4}$, Ziad Darkhabani ${ }^{1}$, Dhruvil J. Pandya ${ }^{1}$ and John R. Lynch ${ }^{1,3,4} *$}

${ }^{1}$ Department of Neurology, Medical College of Wisconsin, Milwaukee, WI, USA

${ }^{2}$ Daniel M. Soref Clinical Neuroscience Fellow at Froedtert Hospital, Froedtert Hospital/Medical College of Wisconsin, Milwaukee, WI, USA

${ }^{3}$ Department of Radiology, Medical College of Wisconsin, Milwaukee, WI, USA

${ }^{4}$ Department of Neurosurgery, Medical College of Wisconsin, Milwaukee, WI, USA

\section{Edited by:}

Syed I. Hussain, Michigan State

University, USA

\section{Reviewed by:}

Johanna Fifi, Albert Einstein College of Medicine, USA

Sushant Kale, Southern Illinois

University, USA

*Correspondence:

John R. Lynch, Medical College of

Wisconsin and Froedtert Hospital

West, 9200 West Wisconsin Avenue,

Milwaukee, WI 53226, USA.

e-mail: jlynch@mcw.edu
Endovascular tumor embolization as adjunctive therapy for head and neck cancers is evolving and has become an important part of the tools available for their treatment. Careful study of tumor vascular anatomy and adhering to general principles of intra-arterial therapy can prove this approach to be effective and safe. Various embolic materials are available and can be suited for a given tumor and its vascular supply. This article aims to summarize current methods and agents used in endovascular head and neck tumor embolization and discuss important angiographic and treatment characteristics of selected common head and neck tumors.

Keywords: coil, liquid embolic, vascular tumors, neuroendovascular

\section{INTRODUCTION}

According to the National Cancer Institute, cancer of the head and neck accounts for $3-5 \%$ of the total cancer incidence in the US (National Cancer Institute, 2011). In 2005, there were 39,000 cases of head and neck cancers. Approximately 19,000 cases of primary brain tumors are diagnosed annually in the US. Angiography and intra-arterial embolization of a tumor contributes in diagnosis, surgical planning, and treatment. Characterization of angiographic features including vascular architecture and flow patterns can contribute to diagnosis. Angiography also provides intricate evaluation of the tumor vascular supply and proximity of neighboring vessels that can be of great value in surgical planning. Intra-arterial embolization is often adjunctive therapy prior to surgical resection. Embolization and devascularization of these tumors can reduce blood loss during surgical resection and improve visualization of the surgical site. In patients who are not candidates for surgical resection, intra-arterial embolization can provide palliative therapy. Endovascular therapies have expanded to include infusions of agents which disrupt the blood-brain barrier that can be used to treat lymphomas, and local intra-arterial chemotherapy infusion which can be utilized to treat squamous cell cancers of the head and neck. The advent of targeted therapies such as anti-bodies, nanoparticles, and gene vectors may herald a new era of intra-arterial delivery of therapeutic agents to these tumors.

\section{PRINCIPLES OF ANGIOGRAPHY FOR HEAD AND NECK TUMORS}

Angiography in patients with head and neck tumors can provide valuable diagnostic and treatment planning information. Careful and exhaustive investigation of all possible tumor supply is important for safe and effective therapy. A complete cerebral angiogram is often necessary including dedicated injections of the internal and external carotid arteries and vertebral arteries bilaterally. Dedicated cervical vessel angiograms may also be necessary depending on tumor location. Tumor vascular supply and recruitment can vary widely and bilateral supply is common, especially in tumors of the midline neck, ethmoid bone, and meningiomas. Superselective micro-catheterization is often necessary for complete evaluation of individual distal vessel supply and to assess for intra-tumoral shunting. Presence of intra-tumoral shunting may increase the risks of embolization. Additionally, close attention should be paid to the presence of anastomoses between extra and intra-cranial circulation or anastomoses to critical structures such as the eye or vaso nervosum supplying various cranial nerves (Table 1).

\section{ANGIOGRAPHIC FEATURES OF HEAD AND NECK TUMORS}

Various angiographic features of head and neck tumors are important in tumor characterization and treatment planning. The vascular architecture can differ widely among tumors and characterization can be helpful in diagnosis. Vascular supply may be encasing, infiltrating, diffuse, focal, dense, patterned, or include various other characterizations. The degree of vascularity also may represent aggressiveness of the tumor. Additionally, bowing or displacement of adjacent vessels may provide insight to the degree of mass effect from the tumor or surrounding edema. Vessel caliber may contribute in understanding chronicity of tumor growth. Multiple large caliber feeding vessels may indicate a slower longstanding progressive growth. A very important element of tumor vascular architecture is anastomosis. A complete understanding of vessel anastomoses associated with the tumor supply is critical in embolization planning to avoid unintended sacrifice of supply to important structures. Figure 1 shows angiograms from a case of embolization treatment for a juvenile nasopharyngeal angiofibroma (JNA). A Vidian artery is noted with anterograde opacification from the left internal carotid artery to the tumor. 
Table 1 | External carotid arteries, associated cranial nerves, and notable anastomoses.

\begin{tabular}{|c|c|c|}
\hline Artery & CN at risk (notable supply pathway) & Notable anastomoses \\
\hline Superior thyroid & X, superior laryngeal nerve branch (superior laryngeal artery) & Contralateral superior thyroid and inferior thyroid arteries \\
\hline Lingual & $\begin{array}{l}\text { XII, extra-cranial segment (multiple branches depending on } \\
\text { regional hemodynamic balance) }\end{array}$ & Contralateral lingual artery, superior thyroid artery \\
\hline Facial & Rare direct $\mathrm{CN}$ association & $\begin{array}{l}\text { Lingual artery, ophthalmic artery, rarely with ascending } \\
\text { pharyngeal }\end{array}$ \\
\hline $\begin{array}{l}\text { Ascending } \\
\text { pharyngeal }\end{array}$ & $\begin{array}{l}\text { IV (via MHT), V, VI (jugular br. and via MHT), VII, VIII, IX (jugular br.), } \\
\text { X (jugular br.), XI (jugular br. and musculospinal br.), XII } \\
\text { (hypoglossal br.) }\end{array}$ & $\begin{array}{l}\text { ICA, VA, MHT, middle meningeal artery, inferior tympanic } \\
\text { artery }\end{array}$ \\
\hline Posterior auricular & VII (stylomastoid br.) & $\begin{array}{l}\text { Meningeal anastomoses with MMA and ascending } \\
\text { pharyngeal }\end{array}$ \\
\hline Occipital & VII (stylomastoid br.) & Trans-osseous to posterior fossa, muscular branches to VA \\
\hline Internal maxillary & III (via ILT), V (artery of foramen rotundum), VI (via ILT) & ICA (via Vidian artery and ILT), ophthalmic artery \\
\hline Middle meningeal & V (cavernous br.), VI, VII (petrous br.) & Recurrent ophthalmic to eye and ICA, ILT \\
\hline Superficial temporal & Rarely via anastomoses to VII and VIII. & Ophthalmic artery via the supraorbital branch \\
\hline
\end{tabular}

CN, cranial nerve; ICA, internal carotid artery; VA, vertebral artery; MHT, meningo-hypophyseal trunk; ILT, infero-lateral trunk; br, branch.

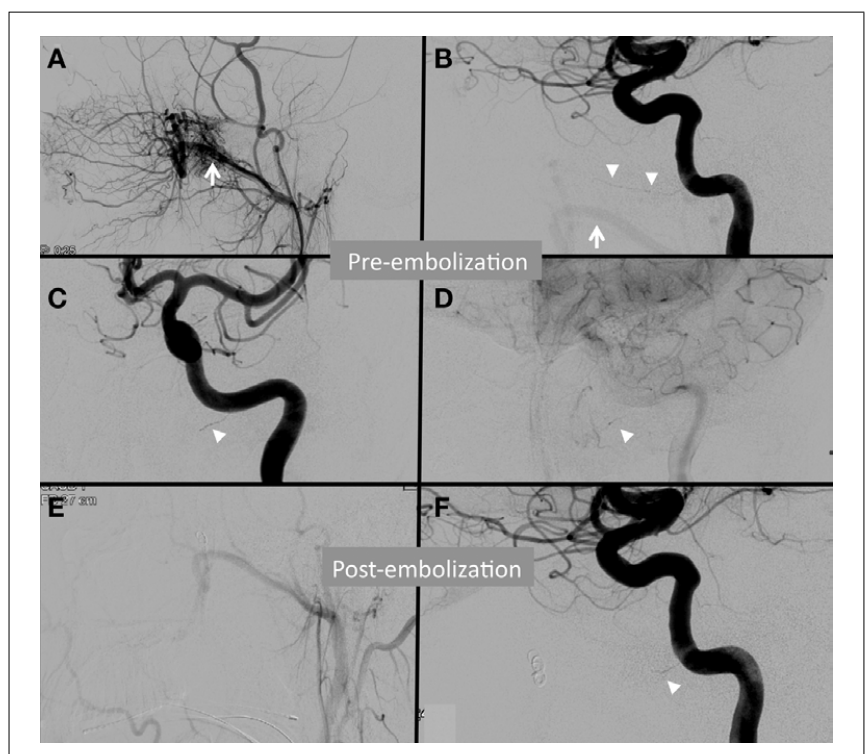

FIGURE 1 | Angiogram from a patient with a juvenile nasopharyngeal angiofibroma (JNA) demonstrating subtle anastomosis between the external and internal carotid arteries via the Vidian artery. The left internal maxillary artery (white arrow) supplies a JNA as demonstrated by the left external carotid artery (ECA) injection (A) and the left internal carotid artery (ICA) injection with reflux (B). A Vidian artery is noted (white arrowheads) in the early arterial phase left ICA injection on lateral (B) and anteroposterior (C) injections. Faint opacification of the tumor arises from the Vidian artery in the capillary phase of the same ICA injection (D). Post-embolization ECA injection (E) demonstrates complete devascularization. Post-embolization, the Vidian artery opacification is attenuated (F).

After embolization, the Vidian artery communication is occluded distally and opacification becomes attenuated. This case illustrates the need for careful embolization of the left external carotid arteries given the possibility of particle material embolizing through the Vidian artery into the intra-cranial left ICA circulation.
In addition to architecture, blood flow patterns can be important. The rate of tumor opacification can be used to characterize the tumor demand. Higher demand tumors may be more susceptible to congestion after embolization, and additionally this feature may be important in surgical planning to reduce blood loss. Intra-tumoral shunting is also important in embolization planning. Embolization techniques will need to be tailored to the degree of venous shunting to avoid unintended embolic material migration or distal embolization into the venous system.

\section{PERTINENT VASCULAR ANATOMY OF HEAD AND NECK TUMORS}

Branches of the external carotid artery are invariably involved with extra-cranial tumors and extra-axial intra-cranial tumors, mainly meningiomas. Middle meningeal and accessory meningeal arteries arising from the internal maxillary artery supply the meninges over the frontal, parietal, and temporal lobes. Trans-osseous branches of occipital arteries may also be recruited for large meningiomas. Posterior meningeal branches arising from the vertebral artery may supply the meningiomas of the posterior fossa. The anterior falcine artery arising from the ophthalmic artery may feed the parafalcine meningiomas located anteriorly. Olfactory groove meningioma may derive blood supply from bilateral ethmoidal arteries.

Nasopharyngeal tumors such as JNA and paragangliomas may derive blood supply from branches of the external carotid artery, specifically the sphenopalatine arteries. Paragangliomas such as glomus jugulare and carotid body tumors may be sustained by branches of the ascending pharyngeal artery. Tympanic paragangliomas and schwannomas are supplied by branches of the ascending pharyngeal, occipital, middle meningeal arteries, as well as the extra-cranial branches of the vertebral artery.

Large tumors may "parasitize" nearby vasculature or preexisting anastomotic connections may undergo dramatic enlargement due to flow demand. Olfactory groove or temporal tip meningiomas may derive blood supply from branches of the 
internal carotid artery such as meningo-hypophyseal trunk or the superior hypophyseal artery. Tumors of nasopharynx may recruit internal carotid artery branches including the infero-lateral trunk or vidian artery. Similarly, tumors of the middle or cerebellopontine angle may be supplied by branches of the anterior inferior cerebellar artery.

Internal carotid artery supply is less common, but may play an important role in vascular supply through branches including the ophthalmic artery and ethmoidal branches, infero-lateral trunk, meningo-hypophyseal trunk, and mandibulovidian arteries.

\section{PRINCIPLES OF EMBOLIZATION}

Tumor embolization will devascularize the tumor and can be used adjunctively with surgical resection or as a palliative measure. Optimal embolization results in tumor devascularization with no visualization of intra-tumoral opacification while avoiding unintended vessel occlusion. Pre-operative tumor embolization for hypervascular neoplasms results in improved surgical outcome, reduced intraoperative blood loss, and facilitates tumor resection (Zahringer et al., 2005). The following guidelines are suggested as indications for tumor embolization: (1) to control surgically inaccessible arterial feeders, (2) to decrease surgical morbidity by reducing blood loss, (3) to shorten the operative procedure time, (4) to increase the chances of complete surgical resection, (5) to decrease the risk of damage to adjacent normal tissue, (6) to relieve intractable pain, (7) to decrease expected tumor recurrence, and (8) to allow better visualization of the surgical field with decreased overall surgical complication (American Society of Interventional and Therapeutic Neuroradiology, 2001).

A thorough understanding of the vessel supply, hemodynamic characteristics, venous outflow patterns, and anastomoses is essential for safe and effective treatment. A strong knowledge of regional vascular anatomy is important as complex vascular variations can often be encountered in head and neck tumors. All possible anastomoses should be comprehensively explored prior to embolization. Particular focus should be placed on identifying ECA to ICA anastomoses that carry potential for devastating unintended intra-cranial embolization.

Embolization approaches include transarterial, direct puncture, and a combination of these methods. Ideal tumor embolization is achieved with occlusion of the very small vessels within a tumor, while sparing supply to normal adjacent tissue. Liquid and particulate embolic materials are effective in penetrating small vessels, and meticulous use of these materials is essential in preventing unintended occlusions. Common practice is to begin with smaller sized embolic material to target small distal vessels and gradually increase particle size in successive injections of embolic material. If blood supply to cranial nerves is suspected, provocative testing can be performed by injecting lidocaine and observing for neurological deficit. If a deficit is elicited the micro-catheter can be re-positioned. Positioning the micro-catheter as close as possible to the tumor bed will help avoid embolization of normal structures.

Most tumor embolizations are performed via the external carotid arterial supply. Branches of the internal carotid artery may supply the tumor but in most instances risk of embolization of these branches may exceed benefit. Time to surgical resection after embolization may vary depending on tumor type, characteristics, and degree of devascularization. Embolization is often performed within $24-48 \mathrm{~h}$ of expected surgical resection. Some data suggest that optimal necrosis for meningiomas requires a longer period of up to 7-9 days after embolization (Kai et al., 2002). Delay in surgical resection may cause swelling due to tumor necrosis and compression of adjacent structures.

\section{EMBOLIZATION MATERIALS}

The unique characteristics of each embolic material offer several options for tumor devascularization (Table 2). Commonly used embolization materials include poly vinyl alcohol (PVA) particles of varying sizes as well as pledgets of gelatin sponge (Gelfoam, Pfizer, New York, NY, USA) and microfibrillar collagen. Liquid embolization agents include, $n$-butylcyanoacrylate (nBCA; Trufill nBCA Liquid Embolic, Codman Neurovascular Inc., Raynham, MA, USA), ethyl vinyl alcohol polymer (Onyx, eV3 Endovascular Inc., Irvine, CA, USA), and ethanol. Occlusion of large vessels may require use of either pushable or detachable coils.

\section{PARTICLES}

\section{POLYVINYL ALCOHOL}

Polyvinyl alcohol particles are embolic agents available in various sizes ranging from $45 \mu \mathrm{m}$ to over $1000 \mu \mathrm{m}$. Use of PVA particles of $45-150 \mu \mathrm{m}$ followed by $150-250 \mu \mathrm{m}$ can be successful in tumor embolization. Smaller particles $45-150 \mu \mathrm{m}$ penetrate the capillary vascular bed of the tumor and aid in devascularization. These particles often devascularize to the extent that the tumor undergoes necrosis. Larger particles 150-250 $\mu \mathrm{m}$ embolize smaller arterioles in the tumor bed. If a dangerous anastomosis is suspected, larger particle sizes can be utilized to prevent accidental embolization of

Table 2 | Commonly used embolic materials and characteristics.

\begin{tabular}{|c|c|c|}
\hline Embolic agent & Advantages & Limitations \\
\hline \multicolumn{3}{|l|}{ PARTICLES } \\
\hline PVA & $\begin{array}{l}\text { Microvasculature penetration } \\
\text { Easy to use }\end{array}$ & $\begin{array}{l}\text { Radiolucent } \\
\text { Irregular shapes may } \\
\text { allow recanalization }\end{array}$ \\
\hline Microspheres & $\begin{array}{l}\text { Microvasculature penetration } \\
\text { Minimal clumping }\end{array}$ & $\begin{array}{l}\text { Fragile } \\
\text { Many are radiolucent }\end{array}$ \\
\hline Gelfoam & $\begin{array}{l}\text { Medium to large vessel } \\
\text { occlusions } \\
\text { Inexpensive, easy to use }\end{array}$ & Temporary \\
\hline \multicolumn{3}{|c|}{ LIQUID AGENTS } \\
\hline \multirow[t]{2}{*}{$\mathrm{nBCA}$} & $\begin{array}{l}\text { Rapid solidification and } \\
\text { occlusion }\end{array}$ & Rapid solidification \\
\hline & $\begin{array}{l}\text { Can flow into complex } \\
\text { angioarchitecture }\end{array}$ & Catheter retainment \\
\hline Onyx & $\begin{array}{l}\text { Slower solidification } \\
\text { Can flow into complex } \\
\text { angioarchitecture }\end{array}$ & Catheter retainment \\
\hline \multicolumn{3}{|l|}{ COILS } \\
\hline \multirow[t]{2}{*}{ Coils } & Precise deployment & $\begin{array}{l}\text { Possible dislodgement } \\
\text { and embolization }\end{array}$ \\
\hline & Useful in high-flow vessels & \\
\hline
\end{tabular}


the anastomosing branches. Good blood flow should be ensured during embolization as anterograde flow in the supplying branches will carry the embolizing material to the target vasculature. Swift sequential injections with minimal delay in syringe changes are important to provide a near continuous and steady administration of particles because occlusion relies partly on particle aggregation. Flow arrest due to vasospasm or any other etiology may lead to reflux and increased risk of embolization of an unintended target.

Use of small particles should be limited to the tumor bed as it may cause necrosis of the overlying skin in cases of extra-cranial tumors. Embolization should be continued until tumor blush disappears or there is prolonged contrast stagnation with increased resistance to further embolization. Tumors deriving blood supply from multiple feeders will require embolization through each of the supplying pedicles.

\section{MICROSPHERES}

Microsphere embolics include trisacryl gelatin microspheres (Embospheres; BioSphere Medical, Inc., Rockland, ME, USA) and a newer hydrogel microsphere with a polymer coating (Embozene; CeloNova BioSciences, Inc., Newnan, GA, USA). These agents are non-absorbable, round, embolic agents with precise size. These agents differ from PVA particles due to uniform size and shape, which theoretically improves distal penetration. The hydrophilic coating of the Embosphere is intended to reduce aggregation and facilitates injection through micro-catheters. They are available in sizes ranging from $40 \mu \mathrm{m}$ to $1300 \mu \mathrm{m}$. Varying sizes of embolics have shown to correlate with vessel size and may allow for identification of a threshold for intra-tumoral penetration of embolics (Laurent et al., 2005). A prospective comparison of trisacryl gelatin microspheres and PVA particles for meningioma embolization reported reduced blood loss at resection and more distal vessel penetration with use of trisacryl gelatin microspheres (Bendszus et al., 2000).

\section{GELFOAM}

Gelfoam is a water-insoluble, porous, and pliable agent that resorbs completely within 4-6 weeks. Occlusion occurs after the gelfoam matrix facilitates thrombus formation. This agent can be used for embolization of highly vascular head and neck tumors for pre-operative resection to reduce blood loss. Both sponge and powder forms have been used in head and neck tumor embolization (Rutka et al., 1985). Gelfoam strips are rolled into a cylindrical shape and advanced through a catheter to the intended location. The Gelfoam powder is injected through a micro-catheter using a similar technique as particle embolism.

\section{LIOUID EMBOLIC AGENTS \\ $\boldsymbol{N}$-BUTYLCYANOACRYLATE}

$\mathrm{N}$-butylcyanoacrylate is a liquid which polymerizes in the ionic and high $\mathrm{pH}$ environment in the body. A mixture of nBCA and ethiodol is prepared and micronized tantalum powder (Trufill; Codman Neurovascular, Inc., Raynham, MA, USA) can be added to increase radiopacity for enhanced visualization. It is a good embolic agent for embolizing branches $0.5 \mathrm{~mm}$ or greater. It may not penetrate the tumor bed due to rapid polymerization upon contact with the blood and therefore an appropriate dilution is

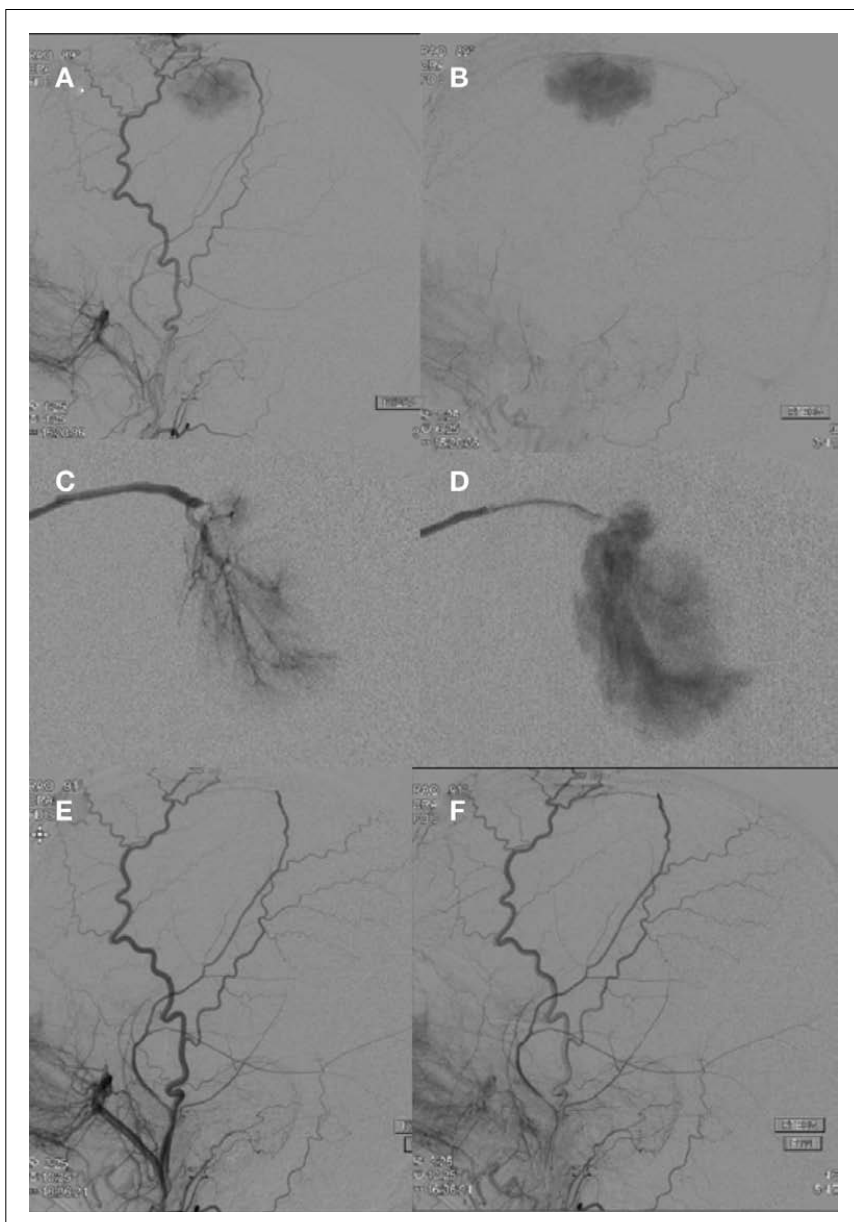

FIGURE 2 | A right external carotid artery injection (A,B) demonstrates a hypervascular, dural-based, left frontal parasagittal tumor consistent with a meningioma. An anteroposterior view of a selective right middle meningeal artery injection shows characteristic features including a prominent core vascular supply with a sunburst appearance (C) and a homogenously intense and prolonged vascular stain (D). A right external carotid artery injection (E,F) performed after PVA particle embolization demonstrates successful devascularization of middle meningeal artery supply to the meningioma.

necessary for effectiveness. This will often demand a dilute preparation of $\mathrm{nBCA}$, however care must be exercised in evaluating the flow dynamics because polymerization time will be extended which could lead to unintended embolization. Embolization of pedicles supplying the tumor can be performed by injecting nBCA. If more than one feeder is present, each of the pedicles would need to be treated separately. Such an embolization approach may be useful in tumors with intra-tumoral shunting in which particle embolization may lead to transmission of particles to the venous system and resulting unintended distal embolization. Furthermore, if large pedicles are embolized, surgical resections should follow in the ensuing days. Delay in resection may lead to angiogenesis and growth of new vascular pathways to the tumoral bed. Embolization of vascular tumors with nBCA has been associated with devascularization rates of up to $90-95 \%$ (Gupta et al., 2007). 


\section{ETHYL VINYL ALCOHOL POLYMER (ONYX)}

Onyx is a liquid embolic agent dissolved in dimethyl sulfoxide (DMSO). Upon contact with the blood, DMSO diffuses out and EVOH polymerizes. This polymer hardens on the outer surface first gradually polymerizing toward the core over several minutes. This property allows longer injections of this material. Using this technique, onyx can be used to embolize tumor bed. This liquid embolic agent can penetrate the tumor bed and can provide controlled embolization of the tumor vascular bed with good penetration. Percutaneous embolization with onyx has also been described.

\section{COILS}

Pushable and detachable coils can be used to embolize large ( $>1.5 \mathrm{~mm}$ ) feeders to tumor beds. Coils afford control and are least likely to embolize distally into the draining veins. They can be an ideal embolization solution for tumors with intra-tumoral shunting. Detachable coils provide more control and can be adjusted during deployment. Coils with bio-active components can provide a nidus for thrombosis and eventual occlusion of the vessel. As with nBCA embolization, coils provide proximal occlusion of the blood supply to the tumor bed without the embolization of the tumor vasculature itself. Therefore, surgical resection should follow coil embolization to minimize the development of collateral blood channels.

\section{ENDOVASCULAR CONSIDERATIONS IN SELECTED TUMORS}

The vascular architecture of head and neck tumors can vary considerably resulting in characteristic angiographic findings. Familiarity with the angioarchitecture of various hypervascular neoplasms of the head and neck can improve embolization planning and success. Careful consideration needs to be given to arterial supply of vital intra-cranial structures and cranial nerves, as well as anastomoses.

\section{MENINGIOMA}

Meningiomas are usually benign intra-cranial or spinal canal tumors characterized by dural attachment, slow growth, and high vascularity. Presentation may be incidental or include headache, focal symptoms related to mass effect, or seizures. There is an increased incidence with age. Locations commonly include the cerebral convexities, falx, and sphenoidal ridges (Kizana et al., 1996). Angiographic characteristics include a well-circumscribed, highly vascularized mass with a homogenously intense, and prolonged vascular stain (Figure 2). A dual vascular supply with dural artery supply to the core and pial artery supply to the periphery may be evident. Enlarged dural arteries may give the appearance of a sunburst or spoke-and-wheel pattern. Pre-operative endovascular embolization for meningiomas is a useful adjunct to tumor resection (Figure 3; Richter and Schachenmayr, 1983). Definitive meningioma treatment commonly involves surgical resection,

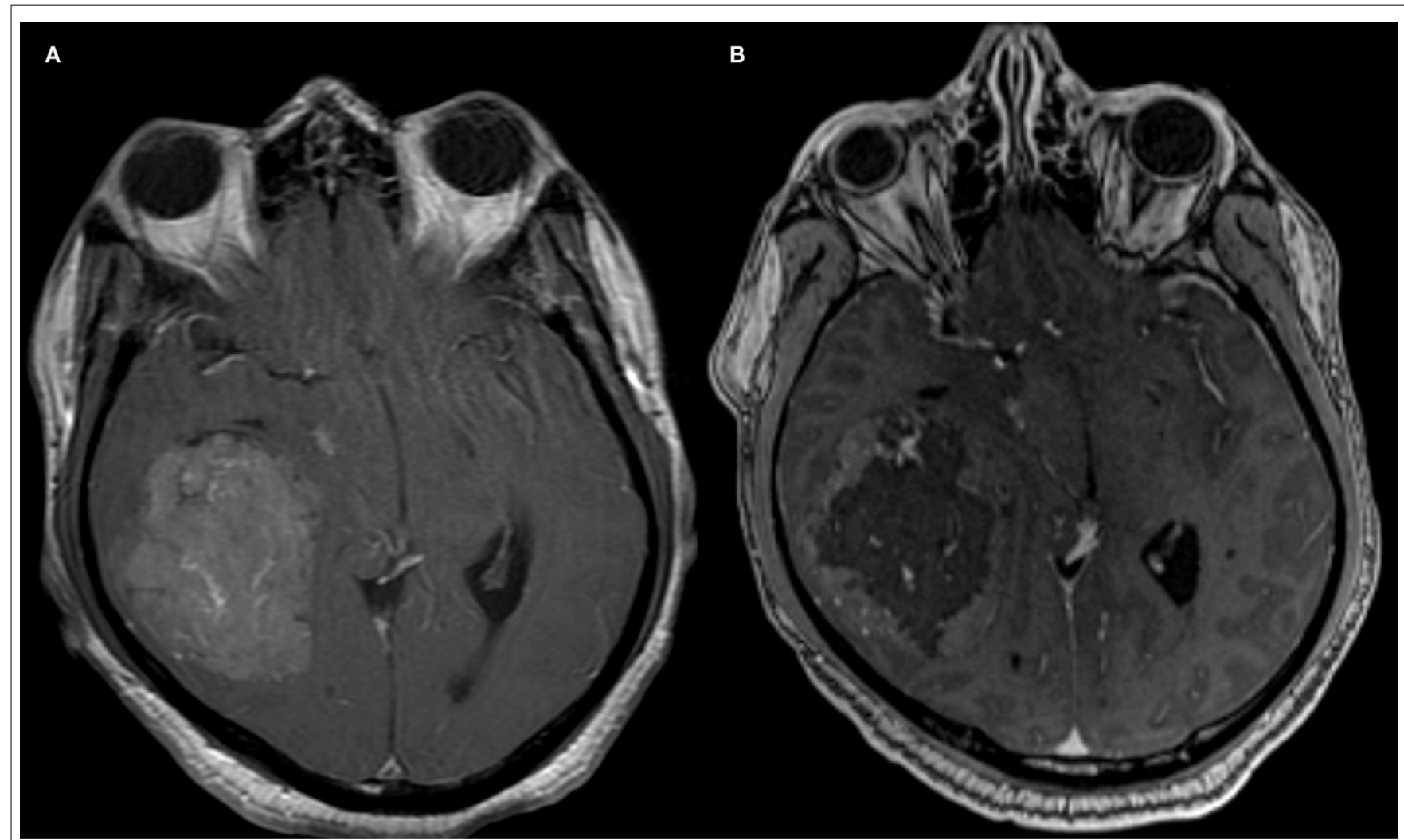

FIGURE 3 | Contrast enhanced MRI images of a middle cranial fossa meningioma obtained before (A) and after (B) endovascular tumor embolization with PVA particles demonstrate devascularization. 
however single modality treatment with only embolization has been reported with tumor shrinkage and clinical improvement in a small series with short-term follow-up (Bendszus et al., 2003). Embolization success will depend on anatomic limitations as well as embolic material. Limitations in achieving complete embolization have involved inaccessible feeding vessels by microcatheter approach and inability to achieve safe superselective micro-catheter positioning to prevent reflux of embolic material into neighboring branches (Gruber et al., 2000). The optimal time interval between embolization and surgical resection is not well defined. A 7-9 day interval has been suggested to allow for optimal necrosis, devascularization, and tumor softening to facilitate resection, however common practice includes surgical resection within $48 \mathrm{~h}$ of embolization (Kai et al., 2002). When absorbable embolic material is used this interval is shortened to prevent recanalization.

\section{HEMANGIOPERICYTOMA}

Hemangiopericytomas are rare tumors derived from smooth muscle pericyte cells around the capillaries of the meninges and therefore were previously termed angioblastic meningiomas (Yousem and Robert, 2010). They are considered to be more aggressive than meningiomas with rates of local recurrence and extra-cranial metastasis around 30\% (Fountas et al., 2006). Clinical presentation varies based on tumor location and may present similarly to a meningioma. Angiographic appearance usually includes relatively few larger vessels with multiple tiny corkscrew-like feeding vessels entering the tumor mass (Figure 4; Marc et al., 1975). An intense fluffy vascular stain with associated lingering contrast of venous channels may be evident. Treatment includes resection and gamma knife surgery (Olson et al., 2010). Pre-operative embolization is used primarily as a method of devascularization to facilitate surgical resection (Chin et al., 1993). Reports in the literature can be elusive due to alternative terminology including angioblastic meningioma and clustering within reports as angioblastic-type meningiomas.

\section{JUVENILE NASOPHARYNGEAL ANGIOFIBROMA}

Juvenile nasopharyngeal angiofibroma is a highly vascular tumor thought to arise from embryonic fibro-cartilage, which may present with nasal obstruction and epistaxis in young males. Surgical resection is the definitive therapy for JNA. Temporary intraoperative external carotid artery clamping during resection has been reported, however pre-operative embolization is widely accepted to reduce intraoperative bleeding and facilitate resection (Ahmad et al., 2008). Angiographic appearance includes a characteristic reticulated pattern in the early arterial phase, with a dense, homogenous blush persisting into the venous phase (Figures 5 and 6). Supply is often from the distal internal maxillary artery branches, accessory meningeal, and ascending pharyngeal. The

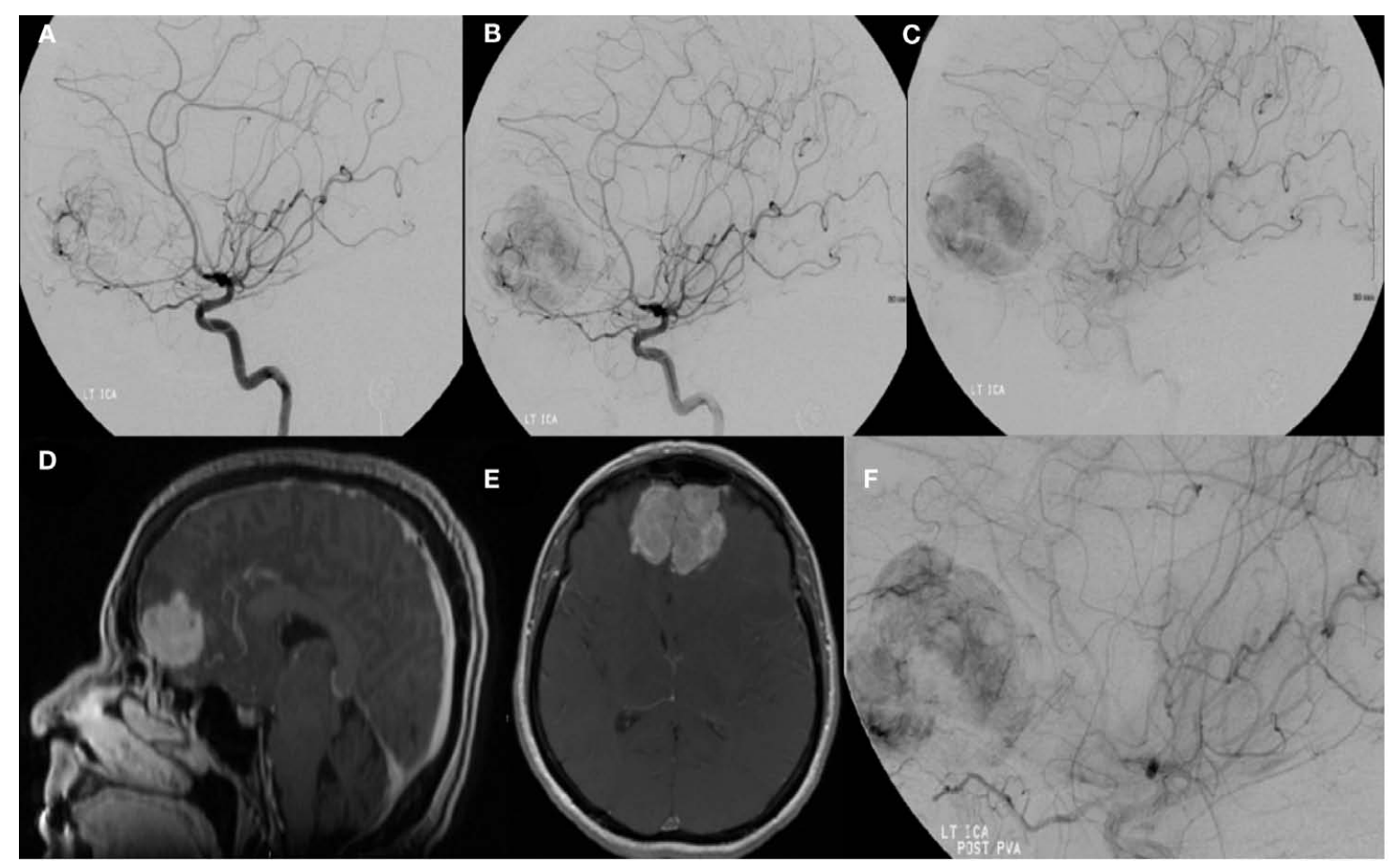

FIGURE 4 | A left internal carotid artery injection demonstrates a highly vascular mass in the region of the anterior cranial fossa predominantly supplied by dural branches from the left ophthalmic artery and branches of the anterior cerebral artery and characteristics consistent with a hemangiopericytoma (A-C). Tumor supply involves relatively few larger vessels with extensive penetration by small branching vessels. Magnetic resonance imaging with contrast shows an enhancing, dural-based, bifrontal mass in the anterior cranial fossa (D,E). The origin of vessel supply from the ophthalmic arteries limited the ability to safely embolize the tumor. Partial pre-operative devascularization was achieved with 45-150 and 150-250 $\mu \mathrm{m}$ PVA particles injected into distal left ophthalmic artery branches supplying the tumor (F). Pathology confirmed hemangiopericytoma. 


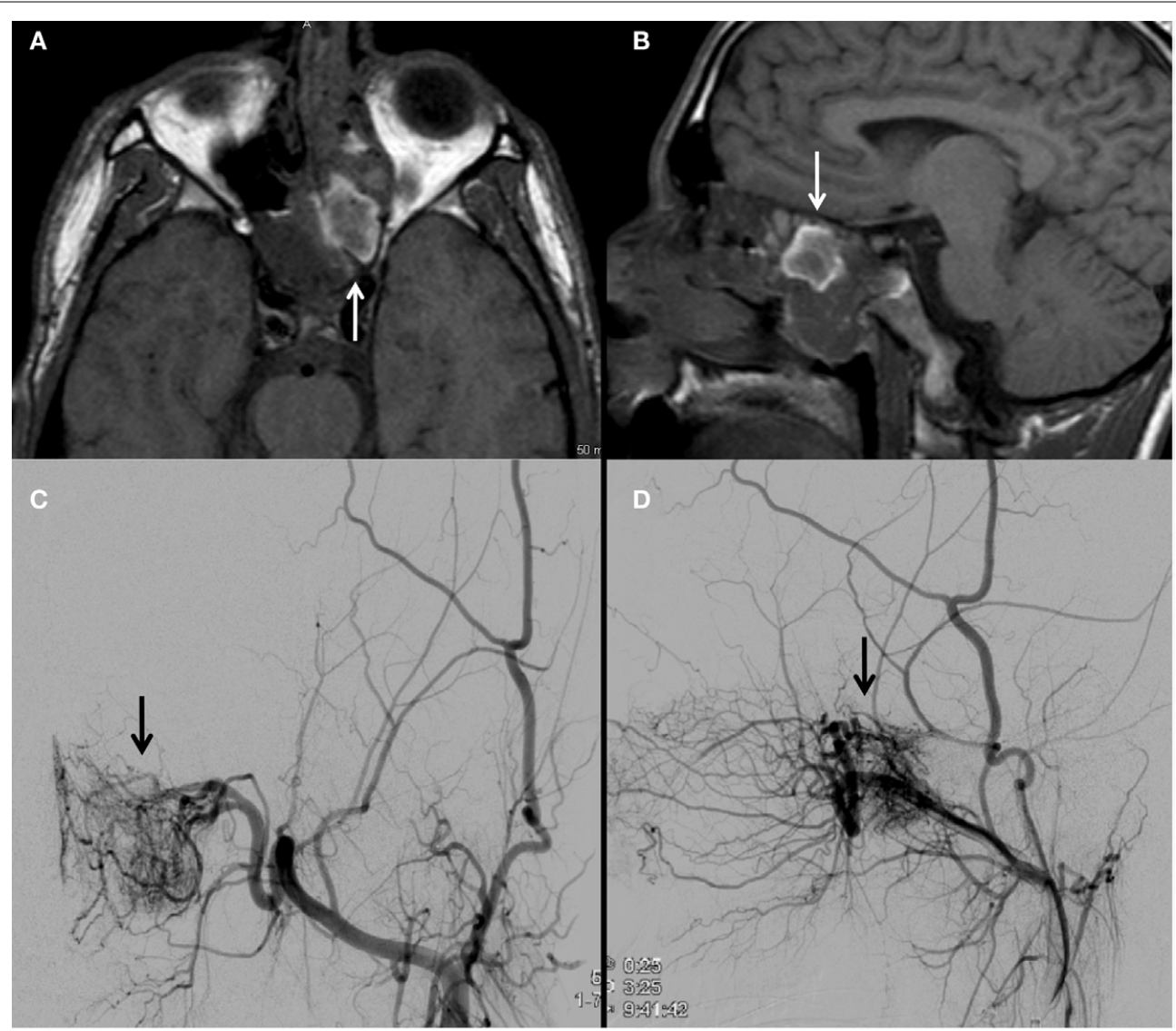

FIGURE 5 | An MRI brain demonstrates a nasal cavity lesion consistent with a juvenile nasopharyngeal angiofibroma (JNA; arrows; A,B). Left external carotid angiogram with anteroposterior (C) and lateral (D) projections demonstrate a hypervascular lesion (arrows) within the left nasopharyngeal region with predominant blood supply from the artery of the pterygoid canal and posterior nasopharyngeal branches of the distal internal maxillary artery. distal internal carotid artery must also be visualized which may show cavernous carotid supply and reveal skull base invasion. A systematic approach has been described and involves embolization of the maxillary artery first to offer the best chance of devascularizing the tumor, followed by selective catheterization and embolization of residual vessels (Davis, 1987). Bilateral embolization may also be necessary if contralateral supply is present. In addition to embolic complications, post-operative low-grade fever and pain in the scalp and face are recognized adverse events associated with JNA (Palmer, 1989).

\section{PARAGANGLIOMA}

Paragangliomas are slow growing tumors of the glomus bodies, which serve as chemoreceptors, and are classified as neuroendocrine tumors. These are most commonly located along the carotid body, jugular foramen, the vagus nerve, and within the middle ear. These may present with swallowing difficulties or hearing loss and tinnitus and occur around the seventh or eighth decade of life. Angiographically, these tumors are characterized by a hypervascular mass with an intense tumor blush (Figure 7). The treatment goal is often complete surgical resection. Pre-operative embolization has been described as adjuvant therapy in these highly vascularized tumors and has been recognized as a method to reduce blood loss and shorten operative time (Tikkakoski et al., 1997). Arterial supply to these structures will vary on location. Commonly involved arteries include the ascending pharyngeal, occipital, posterior auricular, and lingual arteries, while there may rarely be arterial supply from the deep cervical artery and the thyrocervical trunk (van den Berg et al., 2000). Vasa nervorum supply from the involved arteries poses a risk of complication and a lidocaine challenge may be helpful in identifying vulnerable cranial nerves. Embolization may be achieved with particle embolization or Onyx.

\section{COMPLICATIONS}

Complications from endovascular embolization include unintended occlusion from embolic material that can result from reflux of liquid embolic material and small particle size. Temporary balloon occlusion can be used as a technique to control placement of embolic material. Particle size must be chosen appropriately to allow for controlled delivery and catheter placement must be distal to origins of vessels to be preserved. Cranial nerve palsies may result from ischemia to the vasa nervorum and can be reduced with awareness of potentially harmful anastomoses (Table). Major complications include blindness from ophthalmic artery occlusion and ECA to ICA anastomosis emboli resulting in stroke. Minor 


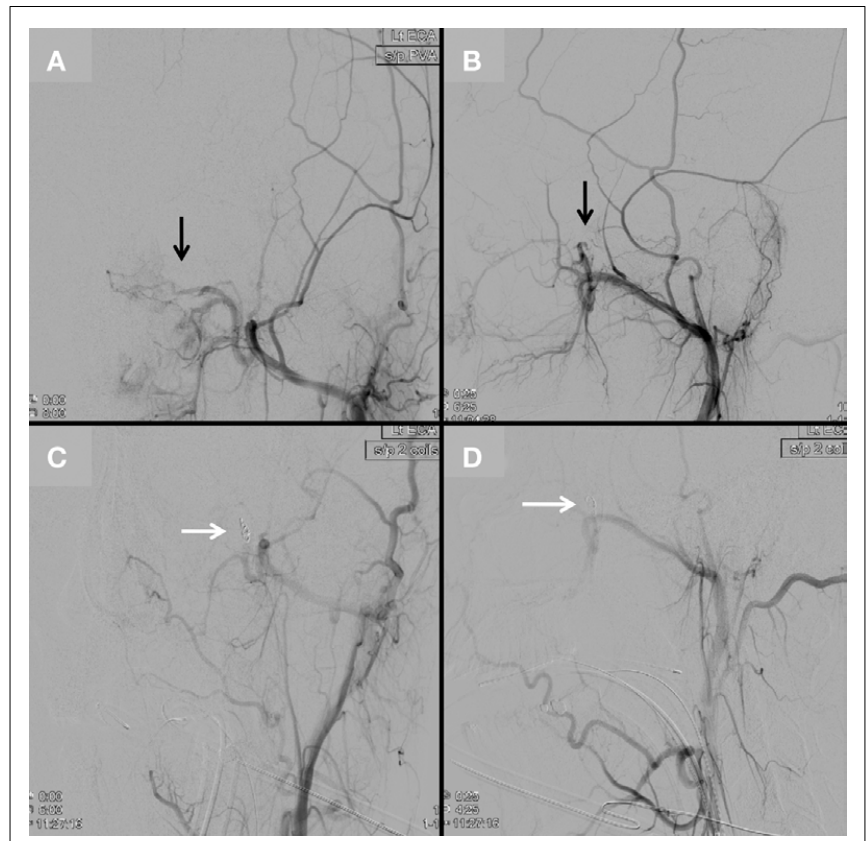

FIGURE 6 | Continued from Figure 5. After superselective embolization with 45-150 $\mu \mathrm{m}$ and 350-500 $\mu \mathrm{m}$ PVA particles, a left external carotid angiogram in anteroposterior (A) and lateral (B) projections demonstrates attenuated contrast opacification of the lesion (black arrows). Two pushable coils were then deployed into the distal internal maxillary artery [white arrows, anteroposterior (C) and lateral (D) projections] to complete embolization of the lesion.

adverse events include facial pain resulting from ischemia and can be managed with appropriate analgesia. Bradycardia from a trigeminocardiac reflex has been reported in association with manipulation of the external carotid artery branches, which likely involves trigeminal nerve afferent tracts to the vagus nerve ( $\mathrm{Lv}$ et al., 2007). This has also been reported with internal maxillary artery embolization. Atropine should be available for severe bradycardia.

\section{INTRA-ARTERIAL CHEMOTHERAPY FOR HEAD AND NECK TUMORS}

Intra-arterial chemotherapy administration could theoretically offer the ability to deliver higher concentrations of pharmacologic agents than would be allowed through an intravenous route and thereby limit systemic toxic side-effects. Superselective microcatheterization of head and neck arterial supply is technically possible for delivery of these agents. Several trials have demonstrated feasibility of this method for adjunctive tumor treatment, however

\section{REFERENCES}

Ahmad, R., Ishlah, W., Azilah, N., and Rahman, J. A. (2008). Surgical management of juvenile nasopharyngeal angiofibroma without angiographic embolization. Asian J. Surg. 31, 174-178.

American Society of Interventional and Therapeutic Neuroradiology.
(2001). Head, neck, and brain tumor embolization. AJNR Am. J. Neuroradiol. 22, S14-S15.

Bendszus, M., Klein, R., Burger, R., Warmuth-Metz, M., Hofmann, E. and Solymosi, L. (2000). Efficacy of trisacryl gelatin microspheres versus polyvinyl alcohol particles in

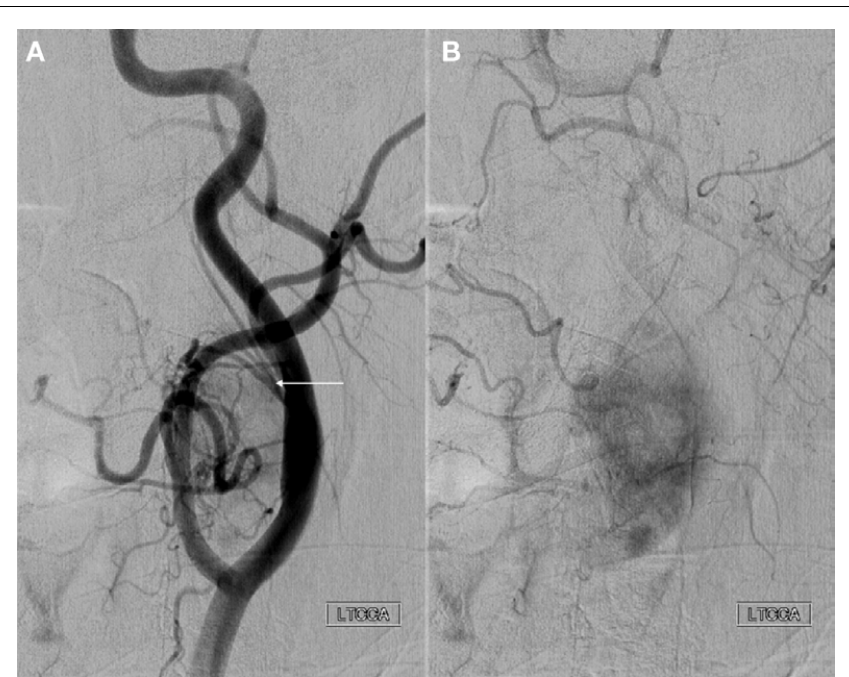

FIGURE 7 | Anteroposterior projection of a left common carotid artery injection demonstrates a large hypervascular tumor at the carotid bifurcation consistent with a paraganglioma. Characteristics including splaying of the internal and external carotid arteries (A) and intense tumor blush (B) are shown. Arterial supply includes branches of the ascending pharyngeal artery (arrow) arising from a common pharyngo-occipital trunk (not shown) that originates from the internal carotid artery.

survival benefit has not been demonstrated and catheter-related complications and long-term effects of neurotoxicity have not been clearly defined (Robbins and Homma, 2008; Robbins et al., 2010). Efforts in nanotechnology research have been explored, specifically using nanoparticle albumin-bound paclitaxel, to more safely deliver high concentrations of intra-arterial chemotherapy, however these agents remain investigational (Damascelli et al., 2007). Alternative methods of improved antineoplastic agent delivery have been explored in systemic administration including molecular targeting and gold nanoparticles as well as gene therapy, and these methods may be augmented with intra-arterial administration.

\section{CONCLUSIONS}

Endovascular embolization for head and neck tumors can provide an effective adjunctive therapy to resection. A thorough understanding of the angioarchitecture of head and neck tumors and neurovascular anastomoses can play an important role in diagnosis and treatment planning. Novel techniques and embolic agents will continue to advance endovascular treatment, and emerging approaches including intra-arterial chemotherapy may expand the endovascular options for cancer therapy.

the preoperative embolization of meningiomas. AJNR Am. J. Neuroradiol. 21, 255-261.

Bendszus, M., Martin-Schrader, I., Schlake, H. P., and Solymosi, L. (2003). Embolisation of intracranial meningiomas without subsequent surgery. Neuroradiology 45, 451-455.
Chin, L. S., Rabb, C. H., Hinton, D. R., and Apuzzo, M. L. (1993). Hemangiopericytoma of the temporal bone presenting as a retroauricular mass. Neurosurgery 33, 728-731; discussion 731-722.

Damascelli, B., Patelli, G., Ticha, V., Di Tolla, G., Frigerio, L. F., Garbagnati, F., Lanocita, R., Marchianò, A., 
Spreafico, C., Mattavelli, F., Bruno, A., and Zunino, F. (2007). Feasibility and efficacy of percutaneous transcatheter intraarterial chemotherapy with paclitaxel in albumin nanoparticles for advanced squamous-cell carcinoma of the oral cavity, oropharynx, and hypopharynx. J. Vasc. Interv. Radiol. 18, 1395-1403.

Davis, K. R. (1987). Embolization of epistaxis and juvenile nasopharyngeal angiofibromas. AJR Am. J. Roentgenol. 148, 209-218.

Fountas, K. N., Kapsalaki, E., Kassam, M., Feltes, C. H., Dimopoulos, V. G., Robinson, J. S., and Smith, J. R. (2006). Management of intracranial meningeal hemangiopericytomas: outcome and experience. Neurosurg. Rev. 29, 145-153.

Gruber, A., Killer, M., Mazal, P., Bavinzski, G., and Richling, B. (2000). Preoperative embolization of intracranial meningiomas: a 17-years single center experience. Minim. Invasive Neurosurg. 43, 18-29.

Gupta, A. K., Purkayastha, S., Bodhey, N. K., Kapilamoorthy, T. R., and Kesavadas, C. (2007). Preoperative embolization of hypervascular head and neck tumours. Australas. Radiol. $51,446-452$.

Kai, Y., Hamada, J., Morioka, M., Yano, S., Todaka, T., and Ushio, Y. (2002). Appropriate interval between embolization and surgery in patients with meningioma.
AJNR Am. J. Neuroradiol. 23, 139-142.

Kizana, E., Lee, R., Young, N., Dorsch, N. W., and Soo, Y. S. (1996). A review of the radiological features of intracranial meningiomas. Australas. Radiol. $40,454-462$.

Laurent, A., Wassef, M., Chapot, R., Wang, Y., Houdart, E., Feng, L., Tran Ba Huy, P., and Merland, J. J. (2005). Partition of calibrated tris-acryl gelatin microspheres in the arterial vasculature of embolized nasopharyngeal angiofibromas and paragangliomas. J. Vasc. Interv. Radiol. 16, 507-513.

Lv, X., Li, Y., Lv, M., Liu, A., Zhang, J., and $\mathrm{Wu}, \mathrm{Z}$. (2007). Trigeminocardiac reflex in embolization of intracranial dural arteriovenous fistula. AJNR Am. J. Neuroradiol. 28, 1769-1770.

Marc, J. A., Takei, Y., Schechter, M. M., and Hoffman, J. C. (1975). Intracranial hemangiopericytomas. Angiography, pathology and differential diagnosis. Am. J. Roentgenol. Radium Ther. Nucl. Med. 125, 823-832.

National Cancer Institute. (2011). National Cancer Institute [online]. Available at: http://www.cancer.gov/ cancertopics/factsheet/Sites-Types/ head-and-neck [Accessed June 21].

Olson, C., Yen, C. P., Schlesinger, D., and Sheehan, J. (2010). Radiosurgery for intracranial hemangiopericytomas: outcomes after initial and repeat Gamma Knife surgery. J. Neurosurg. $112,133-139$.
Palmer, F. J. (1989). Preoperative embolisation in the management of juvenile nasopharyngeal angiofibroma. Australas. Radiol. 33, 348-350.

Richter, H. P., and Schachenmayr, W. (1983). Preoperative embolization of intracranial meningiomas. $\mathrm{Neu}$ rosurgery $13,261-268$.

Robbins, K. T., and Homma, A. (2008). Intra-arterial chemotherapy for head and neck cancer: experiences from three continents. Surg. Oncol. Clin. N. Am. 17, 919-933, xi.

Robbins, K. T., Howell, S. B., and Williams, J. S. (2010). Intra-arterial chemotherapy for head and neck cancer: is there a verdict? Cancer 116 2068-2070.

Rutka, J., Muller, P. J., and Chui, M. (1985). Preoperative Gelfoam embolization of supratentorial meningiomas. Can. J. Surg. 28 441-443.

Tikkakoski, T., Luotonen, J., Leinonen, S., Siniluoto, T., Heikkilä, O., Päivänsälo, M., and Hyrynkangas, K. (1997). Preoperative embolization in the management of neck paragangliomas. Laryngoscope 107, 821-826. van den Berg, R., Wasser, M. N., van Gils, A. P., van der Mey, A. G., Hermans, J., and van Buchem, M. A. (2000). Vascularization of head and neck paragangliomas: comparison of three MR angiographic techniques with digital subtraction angiography. AJNR Am. J. Neuroradiol. 21, 162-170.
Yousem, D. M. Z., and Robert, D. (2010). The Requisites: Neuroradiology, 3rd Edn. Philadelphia, PA: Mosby.

Zahringer, M., Guntinas-Lichius, O. Gossmann, A., Wustrow, J., Kruger, K., and Lackner, K. (2005). Percutaneous embolization for cervicofacial neoplasms and hemorrhages. ORL J. Otorhinolaryngol. Relat. Spec. 67, 348-360.

Conflict of Interest Statement: The authors declare that the research was conducted in the absence of any commercial or financial relationships that could be construed as a potential conflict of interest.

Received: 11 July 2011; accepted: 19 September 2011; published online: 17 October 2011.

Citation: Lazzaro MA, Badruddin A, Zaidat OO, Darkhabani Z, Pandya DJ and Lynch JR (2011) Endovascular embolization of head and neck tumors. Front. Neur. 2:64. doi 10.3389/fneur.2011.00064

This article was submitted to Frontiers in Endovascular and Interventional Neurology, a specialty of Frontiers in Neurology. Copyright (c) 2011 Lazzaro, Badruddin, Zaidat, Darkhabani, Pandya and Lynch. This is an open-access article subject to a non-exclusive license between the authors and Frontiers Media SA, which permits use, distribution and reproduction in other forums, provided the original authors and source are credited and other Frontiers conditions are complied with. 